\title{
BINOMIA E ESTRANHO EM NOITE NA TAVERNA, DE ÁLVARES DE AZEVEDO
}

\author{
BINOMY AND STRANGENESS IN NOITE NA TAVERNA, BY \\ ÁLVARES DE AZEVEDO
}

Danglei de Castro PEREIRA*

\begin{abstract}
Resumo: Este artigo discute traços fantásticos na obra Noite na taverna (1996), de Álvares de Azevedo. Baseia-se nas considerações teóricas de Todorov (2003), bem como na presença da binomia azevediana e do grotesco (HUGO, 1992) como elementos constitutivos da obra e importantes para a análise. Apoiados nos conceitos de sublime (LONGINO, 2020) e grotesco (HUGO, 1992), vislumbramos a presença de elementos estéticos do fantástico estranho (TODOROV, 2003) em nosso corpus. Evitaremos, neste estudo, problematizar a ideia de Longino (2020) quanto ao efeito do extraordinário como marca do sublime. Preferimos, na linha organizacional deste artigo, apontar para a ideia de transcendência ao real imediato em relação ao imagético, nas considerações do autor grego, como ponto de contato entre sua reflexão sobre o sublime e a classificação feita por Todorov (2003) em relação ao fantástico. Como principal percurso metodológico, comentamos o corpus de forma a abordar elementos estilísticos e estéticos no texto de Álvares de Azevedo que mobilizam aspectos como o grotesco, o riso e o estranho, em busca do diálogo entre o real natural e o sobrenatural, entendidos como fatores de construção do universo ficcional de caráter fantástico em Noite na taverna (1996).
\end{abstract}

Palavras-chave: Fantástico. Ficção. Grotesco. Sublime. Narrativa.

Abstract: This paper discusses fantastic features in Noite na taverna (1996), by Álvares de Azevedo. It is based on Todorov's considerations (2003) and takes the presence of Azevedo's binomy as a constitutive element of the work, as well as the presence of the grotesque (HUGO,1992) as important elements for the analysis. Supported by the concepts of sublime (LONGINO, 2020) and grotesque (HUGO, 1992), the presence of aesthetic elements of the fantastic (TODOROV, 2003) were highlighted in our corpus. Problematization of Longino's idea related to the effect of the extraordinary as a mark of sublime was avoided, though; rather, in the sake of the organizational structure of this paper, it points to the idea of transcendence to the immediate real in relation to the imagetic, as considered by the Greek author, as a contact point between his reflections on the sublime and the classification made by Todorov (2003) in relation to the fantastic. The corpus is commented in order to approach stylistic and aesthetic elements in Azevedo's text that mobilize aspects such as the grotesque, the laughter and the strangeness in search of a dialogue between the natural real and the supernatural, which are understood as factors of construction of the fictional universe of fantastic character in Noite na taverna (1996).

Keywords: Fantastic. Fiction. Grotesque. Sublime. Narrative.

\section{Introdução}

O caráter fantástico na obra Noite na taverna, de Álvares de Azevedo, compreende, para o gênero fantástico (TODOROV, 2003), por um lado, a presença de aspectos conflitantes em

\footnotetext{
* Doutor em Letras pela Universidade Estadual Paulista Júlio de Mesquita Filho. Professor na Universidade de Brasília (UnB). E-mail: danglei@unb.br. ORCID: https://orcid.org/0000-0003-1010-1238
} 
relação ao real imediato e, por outro, sua manipulação em direção ao sobrenatural, aspecto que entendemos como presentes no interior da narrativa de Álvares de Azevedo, o que possibilita sua avaliação dentro da teoria do fantástico, conforme Todorov (2003). Entendemos que a narrativa aborda traços do real e os manipula em direção ao sobrenatural, percurso que valoriza, na obra do autor romântico, a apropriação do real via elementos do grotesco, conforme Hugo (1992), como uma das fontes do elemento fantástico em Noite na taverna, eleito como corpus desta discussão.

O percurso analítico abordado no estudo discute a ambientação do corpus ao fantástico e, na medida do possível, a importância da binomia azevediana como influencia na presença do fantástico em Noite na taverna. Cabe ressaltar, ainda, que centraremos nossas colocações na discussão do conceito de fantástico, tomando como referência as ideias de Todorov (2003) em diálogo analítico com os contos que compõem nosso corpus.

Como forma de ambientar nosso leitor, faremos uma breve apresentação das considerações de Todorov (2003) com a intenção de indicar os caminhos teóricos trilhados em nossa discussão. É preciso dizer, ainda, que compreendemos a complexidade do conceito de fantástico, mas selecionamos este caminho teórico como forma a dar objetividade a nossa reflexão.

\section{O fantástico: colocações iniciais}

Como salienta Todorov (2003), o conceito de fantástico está relacionado aos processos de manipulação de real (natural) e da apropriação crítica/reflexiva desse real presente na memória, conforme Le Goff (1990), e na manipulação desses elementos pelo imaginário, em um processo transcendente que se aproxima do não real, ou seja, o sobrenatural. Segundo Todorov (2003), os acontecimentos ambientados em um texto fantástico provocam no leitor uma tênue hesitação entre o natural (tido como real socialmente aceito como natural e, portanto, aceitáveis socialmente) e o sobrenatural (algo que se apresenta fora do universo natural). Em outros termos, o texto fantástico se confronta com a realidade tida como "normal", na medida em que apresenta uma nova realidade, fragmentando, nesse processo, a unidade empírica aceita como natural por uma cultura em um dado contexto social.

Por meio desse diálogo, muitas vezes, tensivo entre o natural e o sobrenatural, Todorov (2003) propõe uma linha de reflexão que classifica por meio de particularidades estéticas e temáticas a diversidade de textos fantásticos. Indica, entretanto, como uma de suas características centrais a tensão entre o mundo aceito como natural e sua transcendência em 
direção ao não-natural. Para o autor, pode-se pensar no fantástico em três níveis: o fantástico puro, o maravilhoso e o estranho.

O texto fantástico puro seria um tipo de texto, no qual o leitor hesita de forma contundente entre o sobrenatural e o natural. No fantástico puro os acontecimentos narrados ampliam os limites do universo natural, ao possibilitarem a compreensão da realidade tida como "real", como frágil ou propensa à expansão. No fantástico puro o leitor não consegue determinar com segurança e de forma plena o conceito de sobrenatural da percepção factível da realidade e, por isso, oscila entre o real - aceito como natural - e o ilusório - aceito como não natural). Nesse processo, percebem-se aspectos da representação natural como uma realidade paralela e factual, mesmo que ficcional. Nesse tipo de texto se enquadrariam, por exemplo, os relatos demoníacos e míticos em essência, pois esses relatos tratam de um tema fora do ambiente natural, mas com força sugestiva suficiente para induzir e confundir o leitor quanto à possibilidade de se apresentarem como naturais em um contexto específico de enunciação, o que, muitas vezes, entra em choque com sua visão cultural de mundo.

No fantástico maravilhoso, outra modalidade do fantástico, segundo Todorov (2003), a consciência racional acabaria por compreender as cenas narradas como elementos basicamente sobrenaturais e pertencentes, por isso, aos espaços da imaginação e transcendência, via percepção e acordo de literariedade.

A realidade diegética no fantástico maravilhoso é tomada como uma abstração face ao traço natural, prevalecendo o sentido de invenção, de confronto com a realidade ao assumirem pactos narrativos que tendem ao não-natural aceito como invenção e, por isso, fixados no pólo dialético do não natural, ou seja, o sobrenatural. Um exemplo de textos maravilhosos está nos Contos de Fadas, nos relatos lendários e nas Fábulas. Nesses textos, o conceito de verdade, sempre relativo e contraditório no gênero fantástico, conforme Todorov (2003), os fatos naturais no universo diegético são suplantados pelo pacto narrativo que, por sua vez, implementa aos relatos a predominância do elemento ilusório e sobrenatural, "era uma vez", por isso, maravilhoso.

Situado no pólo dialético oposto estaria o fantástico estranho. Para Todorov (2003), na medida em que a consciência natural concebe as cenas narradas como parte integrante do real natural, o elemento sobrenatural puro é questionado, situando os acontecimentos descritos na narrativa como parte integrante da realidade; uma realidade diferente, porém aceita como possível, natural. Os textos estranhos, nesse sentido, são representações de realidades complexas, mas que não apresentam dados suficientes para provocar a hesitação do leitor diante do real natural, de forma a configurar o espaço do fantástico puro. 
Um enredo que traz como personagem central um homem de duas cabeças pode figurar como exemplo de um texto fantástico estranho, seguindo o raciocínio de Todorov (2003). Nesse caso, o enredo, mesmo possuindo algo sobrenatural (dificuldade de existirem homens de duas cabeças), é ordenado por um viés racional, pois não se descarta racionalmente a possibilidade da existência desse personagem em um percurso de justificativa ficcional de uma anomalia física, por exemplo, um personagem siamês. As explicações, nesse caso, tenderiam a racionalizar o evento, buscando, por isso, razões e possíveis origens biológicas para a anormalidade física da personagem.

Um exemplo de texto na ambiência do fantástico estranho seria o conto "O gato preto", de Edgar Allan Poe. Nesse conto, mesmo admitindo a existência do fantasmagórico no enredo, ao final podemos aventar a possibilidade racional do felino ter sido emparedado juntamente com o corpo da personagem morta e, por isso, sua presença pode indicar certa linha racional de fundo natural.

Se pensarmos na configuração do grotesco, na concepção cunhada por Victor Hugo (1992), ou seja, como algo que choca o leitor e questiona o conceito clássico de belo, as colocações de Longino (2020), em relação ao sublime, indica que uma face do elemento fantástico é a presença de elementos grotescos como instrumentos importantes na contraposição ao belo. Isso possibilita pensar o fantástico como tensão em relação ao sublime e o leva a apresentar aspectos do extraordinário na manipulação das relações entre o "natural" e o não-natural na configuração estética do fantástico, sobretudo, quando pensado na manipulação do real/natural no fantástico estranho e, por correlação, no conceito de fantástico na classificação proposta por Todorov (2003).

Evitaremos problematizar, neste estudo, a ideia de Longino (2020) quanto ao efeito do extraordinário como marca do sublime e do belo, bem como a presença de uma relação polêmica face à transformação do belo em grotesco, por meio do humor no fantástico, conforme Todorov (2003). Preferimos compreender a ambiência do fantástico e, por vezes, do extraordinário como uma das faces da categorização de fantástico em Todorov (2003) e pensar a ideia de transcendência ao real imediato em relação ao imagético. Portanto, na discussão do corpus, abordaremos o extraordinário, como aspecto inerente à forma como Álvares de Azevedo ambienta seus personagens em Noite na Taverna. Lembramos, ainda, que não problematizaremos, neste texto, a presença da ficção realística como marca de transcendência no fantástico, conforme Cortazar (1982), sobretudo, por compreender que Cortazar (1982) pensa o real como simulacro das tensões imagéticas, o que dá uma conotação transcendente à manipulação do real via extraordinário em sua linha de reflexão. 
Para efeitos de organização de nossa reflexão, embora concordando com Cortazar (1982) em alguns aspectos, principalmente no que se refere à presença do extraordinário e do insólito na construção do riso irônico no fantástico, pensamos o contraponto entre as colocações de Cortazar (1982) e Longino (2020), em sua percepção da transcendência no sublime como aspecto subjacente à classificação feita por Todorov (2003).

Lembramos, para isso, como salienta Hugo, que no grotesco

\begin{abstract}
a musa moderna verá as coisas com um olhar mais elevado e mais amplo. Sentirá que na criação nem tudo é humanamente belo, que o feio existe lado a lado com o belo, o disforme junto do gracioso, o grotesco a par do sublime, o mal simultaneamente com o bem e a sombra com a luz. (HUGO, 1992, p. 115).
\end{abstract}

O olhar grotesco apresenta uma realidade que deforma os padrões normais e, por vezes, tende a chocar-se com o belo, gerando, nesse processo, uma reorganização da própria realidade aparente, na qual a "simultaneidade" indica a reorganização da visão objetiva face ao real, presente no sublime, em Longino (2020), e apontada por Hugo (1992, p. 115), como "humanamente belo".

Diante disso, podemos dizer que na configuração do estranho, em Todorov (2003), o artista pode valer-se do elemento grotesco como forma de intencionalmente questionar a realidade natural. A presença do predomínio racional, dessa forma, indica a existência de um olhar consciente que ordena a apreciação diegética por parte do leitor, em um distanciamento do que Hugo (1992 p. 115) caracteriza por "olhar mais elevado e amplo", em face da idealização clássica no conceito de sublime em Longino (2020).

No fantástico, o leitor compreende o texto estranho como um prolongamento natural da realidade e, por isso, amplia a própria consciência face ao mundo empírico, ao admitir novos arranjos reais. Existe, assim, um princípio reflexivo de cunho silogístico que norteia a construção do fantástico, sobretudo, o fantástico estranho.

No fantástico estranho, os acontecimentos narrados, em um primeiro momento, apresentam-se como sobrenaturais, para posteriormente implicar, por meio da interação com o leitor e seus questionamentos face ao real natural, em uma gradativa incorporação do que primariamente é visto como sobrenatural em direção ao elemento natural e, por fim, se processar uma síntese, na qual o pêndulo natural suplanta o sobrenatural, configurando-se o estranho e reconhecendo-se aspectos naturais no universo narrado que, por isso, são justificados racionalmente como possíveis na realidade aceita como natural. 


\section{Ambiência ao fantástico estranho: o encadeamento dos relatos}

Feitas as colocações preliminares sobre o âmbito do fantástico em Todorov (2003), e, pensando o conceito de grotesco conforme Hugo (1992), iniciaremos a discussão de Noite na taverna, pensando, neste percurso, na presença do fantástico estranho na obra. Um primeiro elemento que nos chama a atenção é a epígrafe que abre Noite na taverna. Nela, vislumbramos a convivência entre o teor racional e o caráter emotivo ligado ao tom passional que envolve os relatos que se sucedem como elementos norteadores da organização global da moldura ${ }^{1}$ narrativa dos textos na obra.

Então, Horácio, estais tremendo e todo branco? Não é algo mais que uma simples ilusão? Que vos parece agora?” (SHAKESPEARE, 1976, p. 16. Tradução de Péricles Eugênio da Silva Ramos). ${ }^{2}$

A epígrafe evoca uma passagem do primeiro ato de Hamlet, no qual os personagens oscilam entre aceitar como verdade a presença de um fantasma que vaga pelo castelo à noite. Azevedo indica nessa oscilação uma ambiência narrativa para seus contos e, de certa forma, anuncia aos leitores que as ações presentes na obra serão fruto de uma imagem nebulosa entre o real imediato e o sobrenatural. Nesses contos, os "convivas" apresentam acontecimentos, no mínimo inusitados, mas com naturalidade, de forma a buscar, por vezes, ancorar os fatos narrados em espaços de verossimilhança em um flerte à plausibilidade.

Entendemos que estes acontecimentos configuram situações narrativas insólitas, oscilando entre o real e o sobrenatural. Como salienta Adonias Filho (1996), o teor das narrativas em Noite na taverna gira em torno de uma temática amorosa ambientada em cenários confusos que se aproximam a sonhos ou alucinações. A essa temática amorosa se associa o elemento trágico, uma vez que nos contos invariavelmente ocorre a morte ou abandono de uma das personagens envolvidas em uma trama passional.

Em "Uma noite do século", conto que abre a narrativa, são apresentados o cenário e os personagens da obra. Essas personagens relatam acontecimentos situados no passado e recuperados pela memória. O espaço narrativo de "Uma noite do século" é identificado como

\footnotetext{
${ }^{1} \mathrm{O}$ romance ou relato de moldura é um tipo de narrativa organizada em torno de um narrador, geralmente, heterodiegético, que cede a voz aos personagens circunscritos a determinado espaço e tempo narrativo. Um exemplo de narrativa de moldura seria As mil e uma noite, de autoria desconhecida, e Decameron, de Giovanni Boccaccio, para citarmos dois exemplos. Entendemos que Noite na taverna é uma narrativa de moldura, aspecto que retomaremos em estudos futuros.

${ }^{2}$ No original: "How now Horatio? You tremble and look pale. Is not this something more than phantasy Walt think you of it?"
} 
uma taverna, mas o tempo narrativo é ambientado à noite em um percurso cronológico. A enunciação, entretanto, recupera pela memória, relatos individuais das personagens que tomam a palavra em turnos distintos para apresentar seus relatos na obra. Nesses relatos individuais, o espaço ambíguo é ligado a elementos externos à taverna, à noite e à embriaguez das personagens. A moldura narrativa ocupa um lugar de destaque na narrativa, uma vez que cria a ambiência que envolve os textos e possibilita a aproximação entre as diferentes focalizações narrativas no conjunto de textos.

Os contos, no entanto, relacionam-se com o conto introdutório, na medida em que retomam, por meio da moldura, diálogos, à noite, em uma taberna, sob influência do ópio e do vinho, contribuindo para a ambientação ao insólito como espaço tensivo em relação à realidade imediata descrita na primeira cena de "Uma noite no século". Um elemento que comprova a ligação entre os relatos é o último conto do conjunto de narrativas que retoma "Uma noite no século", fato que acaba por estabelecer uma ligação entre os relatos da obra, confirmando a moldura para as narrativas e justificando o aparente caos narrativo imposto pela sucessão de vozes nos relatos. Dessa forma, em Noite na taverna, os relatos, aparentemente dispares, são agrupados por meio da mediação estabelecida pelo cenário do conto inicial e pelo narrador heterodiegético que paira entre as personagens, em uma apresentação onisciente das ações que se sucedem.

A recorrente solicitação de "vinho" e as alusões ao estado de embriaguez das personagens, observável ao longo de toda a narrativa, funcionariam, nesse sentido, como linhas coesivas que corroborariam para a unidade global dos relatos em relação à moldura. "Solfieri", por exemplo, primeira personagem a relatar suas experiências, adverte que seu relato "não é um conto" fantástico, mas "uma lembrança do passado".

A ideia de lembrança e refração da memória nas narrativas cria um sentido de dúvida em relação à veracidade dos relatos, aspecto importante que acaba por descaracterizar o traço sobrenatural puro no conjunto de narrativas, ao condicioná-lo ao mecanismo inventivo do narrador heterodiegético que cede o turno para que as demais personagens relatem suas aventuras em narrativas autodiegéticas.

No processo de verificação deste percurso, poder-se-ia levantar a hipótese de que Noite na taverna se enquadraria como sendo uma narrativa fantástica no âmbito estranho, conforme Todorov (2003). Para isso, compreendemos o estranho, em Noite na taverna, na medida em que o leitor é colocado diante de um jogo dialético entre real e sobrenatural que oscila entre o caráter sobrenatural dos relatos e sua aparente plausibilidade, o que indica racionaliza os 
relatos em torno do fantástico estranho, tendo como paradigma importante a presença da moldura narrativa.

A moldura apresentada em "Uma noite do século" aponta para a sobreposição do pendor racional face ao elemento místico inerente a todos os contos na obra. Para nós, este conto propõe a sobreposição do traço racional ao traço sobrenatural/ilusório, na medida em que alinha os relatos e impõe os percursos de retomada na dinâmica dos encadeamentos narrativos na obra de Álvares de Azevedo. Além disso, atitudes como as de "Johann" e "Solfieri” remetem a crítica à crença unilateral em fatos sobrenaturais ou divinos, indicando ao leitor que se trata de fatos ficcionalmente ligados ao natural.

Pode-se pensar, então, que, em Noite na taverna, os encadeamentos narrativos indicam que o traço sobrenatural acaba por ser condicionado a uma perspectiva racional. Em "Uma noite do século", essa racionalidade pode ser verificada se observarmos as palavras de "Bertram" que ridiculariza a crença no sobrenatural, ao propor que a "verdadeira filosofia é o epicurismo", ou seja, "o fim do homem é o prazer" em uma explicita alusão ao "carpe diem" horaciano.

O mesmo "Bertram" afirma que a realidade sobrenatural pode ser produto de alucinações, pois "é fichtismo na embriaquez!...." "Solfieri”, caracterizado como um cético e incrédulo, desdenha da "imortalidade da alma" e das crenças não racionais, chegando a indicar a inexistência do Deus cristão, que, segundo a personagem, é idolatrado em demasia. Nas palavras convulsas de "Johann", teríamos outro exemplo desse predomínio racional inerente aos relatos, pois esse personagem resume o traço sobrenatural à miséria "das verdades religiosas".

Essa tendência à lucidez contrasta com o ambiente insólito no qual se desenvolve os relatos que compõem Noite na taverna. O último diálogo de "Uma noite do século" é ilustrativo quanto a essa tendência, pois "Solfieri" adverte os demais quanto a veracidade dos fatos que são narrados em seu diálogo, uma vez que, segundo ele, seu relato é "uma lembrança do passado"; "vago na alma" (1996, p. 17) e, por isso, devem ser questionados e não aceitos em sua totalidade enunciativa, o que problematiza a presença do sobrenatural nos relatos que se seguem.

O constante questionamento diante do traço sobrenatural, em "Uma noite do século", pode ser percebido no encadeamento dos diálogos contidos no conto. Em determinados momentos, as personagens adotam uma atitude ingênua, expressando uma postura contemplativa diante da realidade. Para Adonias Filho (1996), essa atitude implica na utilização dos clichês da segunda geração romântica. Nessa geração, profundamente 
egocêntrica, prevalece a alienação subjetiva diante da realidade. Entretanto, esses momentos de egocentrismo são suplantados por uma visão irônica que implica na revisão dos padrões puramente subjetivos e alienantes, que são organizados a buscar o diálogo entre os relatos na obra.

Essa visão pode ser percebida no diálogo inicial de "Uma noite do século":

- Cala-te, Johann! Enquanto as mulheres dormem e Arnold-o-louro cambaleia e adormece murmurando as canções de orgia de Tieck, que música mais bela que o alarido da saturnal? Quando as nuvens correm negras no céu como um bando de corvos errantes, e a lua desmaia como a luz de uma lâmpada sobre a alvura de uma beleza que dorme, que melhor noite que a passada ao reflexo das taças?

- És um louco, Bertram! Não é a lua que lá vai macilenta: é o relâmpago que passa e ri de escárnio às agonias do povo que morre ... aos soluços que seguem as mortalhas do cólera!” (AZEVEDO, 1996, p. 13).

Nesse fragmento, observamos a presença do real em tensão à alucinação de Bertram, encontrando um contraponto na fala de Johann. Bertram faz referência não só à obra de Tieck, mística e demoníaca, como também uma alusão comparativa estabelecida entre nuvens e "um bando de corvos errantes". Porém, a atitude mística é suplantada pela dinâmica racional de Johann, imposta pela narrativa e metaforizada pela imagem da "mortalha do cólera". Essa sobreposição do real ao sobrenatural é verificada de forma específica quando "Johann" alude à loucura do conviva, “- És um louco, Bertram! Não é a lua que vai macilenta: é o relâmpago que passa e ri de escárnio às agonias do povo que morre ...”.

O narrador, valendo-se do riso e, por vezes, da ironia, questiona, por meio de uma descaracterização satírica, a valorização unilateral do clichê egocêntrico e do processo alucinatório que envolve as personagens. Solfieri seria um exemplo dessa atitude irônica presente no texto ao se dirigir a presença da confusão mental de Archibald. Em suas intervenções, Solfieri tende a ridicularizar o pendor emotivo que cerca as colocações de Archibald, ao ver apenas a materialização natural das atitudes humanas, metaforizadas na cena de sexo "mulher seminua trêmula e palpitante sobre os joelhos", em detrimento das imagens nebulosas que parecem figurar como ponto de enunciação entre os relatos em uma perspectiva passional.

-Archibald! Deveras que é um sonho tudo isso! No outro tempo o sonho da minha cabeceira era o espírito puro ajoelhado no seu manto argênteo, num oceano de aromas e luzes! Ilusões! A realidade é a febre do libertino, a taça na mão, a lasciva nos lábios, e a mulher seminua trêmula e palpitante sobre os joelhos (AZEVEDO, 1996, p. 16) 
Vislumbrarmos, nesse excerto, como se implementa uma gradativa redefinição dos elementos emotivos e insólitos contidos no seio de Noite na taverna. O elemento puro e contemplativo, “oceano de aromas e luzes!", cede lugar a uma visão crítica centrada na compleição racional que redefine essas impressões, imprimindo, com isso, uma visão pautada pela sátira, diante da ingenuidade da contemplação mística da realidade descrita, inclusive, como "a febre do libertino", em contraposição aos "aromas e luzes", ou seja, às "ilusões".

A "realidade", descrita como a "a febre do libertino", indica a permuta entre sono e lucidez das personagens envolvidas nos contos de Noite na taverna, sob a égide do noturno e de uma profusão quase caótica dos diálogos entre ébrios, que acabam por contribuir para a implementação de um olhar alucinado aos relatos, mas inseridos como possíveis na moldura narrativa.

O traço sobrenatural alienante e insólito, em nossa linha analítica, é suplantado pela racionalização dos percursos diegéticos e em muito justificado pela embriaguez das personagens. Os relatos, apesar da aparência sobrenatural, são submetidos a um processo racional de composição, como lembra "Solfieri", são frutos da imaginação, mas na linha diegética dos contos remontam às memórias das personagens.

O relato de "Solfieri", por exemplo, aborda uma aventura amorosa com uma cataléptica confundida como morta pela personagem. "Bertram" é envolvido por amores adúlteros, porém o final trágico e a cena de canibalismo que encerram o relato, apesar do traço grotesco, enquadram-se como uma necessidade de sobrevivência e, nesse caso, embora o texto se apresente como um grande aglomerado de desgraças, o pendor racional acaba por sustentar o encadeamento das ações.

Nos contos de Noite na taverna, em nossa linha de leitura, o sobrenatural acaba sendo gradativamente amenizado por um encadeamento racional e dialético das ações, fato que reforça a abordagem dos textos dentro do fantástico estranho.

Esse jogo dialético pode ser verificado no relato que segue:

- Não te lembras, Bertram, de uma forma branca de mulher que entrevistes pelo véu do meu cortinado? Não se lembras que eu te respondi que era uma virgem que dormia?

- E quem era essa mulher, Solfieri?

- Quem era? Seu nome?

- Quem se importa com uma palavra quando se sente que o vinho queima assaz os lábios? Quem pergunta o nome da prostituta com quem dormiu e sentiu morrer a seus beijos, quando nem há dele mister por escrever-lho na lousa?

Solfieri encheu uma taça e bebeu- a. Ia erguer-se da mesa quando um dos convivas tomou-o pelo braço.

- Solfieri, não é um conto isso tudo? 
- Pelo inferno que não! Por meu pai que era conde e bandido, por minha mãe que era a bela Messalina das ruas, pela perdição que não! Desde que eu próprio calquei aquela mulher com meus pés na sua cova de terra, eu vo-lo juro! - guardei-lhe como amuleto a capela de defunta. Ei-la!

Abriu a camisa, e viram-lhe ao pescoço uma grinalda de fores mirradas.

- Vedes? Murcha e seca como o crânio dela! (AZEVEDO, 1996, p. 23).

Nesse fragmento, vislumbramos a busca pelo teor de "verdade" implementado pelos diferentes narradores aos relatos contidos em Noite na taverna, mas entendemos que estes relatos são mediados pelo narrador heterodiegético. O narrador heterodiegético procura situar o leitor diante do quadro que se apresenta. O confronto entre Solfieri, que relata sua experiência passada e a dúvida imposta pelos ouvintes quanto a veracidade dos fatos narrados, é suplantada pelo apelo a "grinalda de flores mirradas" que procura atestar a verdade do relato de Solfieri.

A "grinalda de flores", nesse sentido, juntamente com as juras e o tom exaltado de “Solfieri”, corroboram para a caracterização das ações como pertencentes à realidade natural. Pode-se dizer, então, que as sucessivas narrativas que compõem a obra engendram um ciclo, no qual as personagens são destituídas de seus traços convencionais para compor, no ambiente conturbado da taverna e da embriaguez, uma organização discursiva que, em certa medida, remete ao predomínio do racional diante do sobrenatural, configurando, com isso, o traço estranho presente na obra.

O confronto entre racional e sobrenatural, presente em Noite na taverna, acaba por revelar uma postura consciente no que se refere ao engendramento das ações relatadas nos contos da obra em discussão. Esse comportamento denota o que o próprio Álvares de Azevedo, no prefácio da segunda parte da Lira dos vinte anos (1998), denominou por binomia, ou seja, a presença do percurso racional em diálogo com o traço emotivo em sua obra.

A binomia azevediana estaria centrada na valorização do processo racional em detrimento dos pendores puramente emotivos inerentes a composição romântica. Essa tendência à racionalização pode ser verificada, em Álvares de Azevedo, a partir da segunda parte da Lira dos vinte anos. Vanger Camilo comenta que Álvares Azevedo defende, no prefácio da segunda parte da obra azevediana, uma postura mais crítica diante da emotividade romântica. Segundo o crítico, essa atitude revela "o esgotamento (tendência inscrita no tempo) da temática amorosa, do idealismo e do sentimentalismo à Chateaubriand" (CAMILO, 1997, p. 57). 
Álvares de Azevedo, nesse prefácio, adverte o leitor para o fato de que sua poética reorganiza os valores emotivos para atingir uma expressão, mais próxima dos traços combativos presentes no seio do pensamento romântico. A advertência denotaria, assim, na mudança de tom inerente a sua obra, pois, para o poeta, o fazer literário passa a ser reflexo de uma postura mais lúcida diante da realidade e dos padrões excessivamente emotivos presentes na tradição romântica.

Essa noção, em nosso ponto de vista, norteia a composição de Noite na taverna. Pensamos a obra em análise à luz da binomia azevediana e, por isso, somos levados a considerar a existência de uma reorganização dos traços emotivos presentes no discurso romântico via manipulação do fantástico em nosso corpus. Estaríamos, assim, diante de um discurso ficcional, no qual prevalece o traço racional; mas sobre a ambiência do sobrenatural, por isso, fantástico estranho.

Essa observação ganha força se interpretarmos o último conto da narrativa como o resultado da ascendência da razão face ao sobrenatural no interior de Noite na taverna. Esse conto está intimamente relacionado com o conto anterior e nos ajuda a pensar o encadeamento de leitura destinado a nosso corpus, pois funciona como um prolongamento, no presente da narração, das consequências racionais das ações realizadas no passado pelas personagens no tempo da enunciação.

Esta dicotomia, passado e presente, é materializada no penúltimo conto da obra ao apresentar a mulher que inesperadamente surge na taverna e mata "Johann", como a mesma que no conto anterior, fora descrita como sua irmã. Esta nuance é outro argumento em favor da presença do fantástico estranho no conjunto de narrativas de Noite na taverna.

\section{Considerações finais}

Ao finalizar este artigo, pensamos que Azevedo, ao privilegiar o elemento racional na organização de Noite na taverna, materializa uma reestruturação da ambiência insólita dos acontecimentos narrados, em direção à cronologia temporal que se materializa na leitura global dos relatos dos "convivas" em uma perspectiva global alinhada à moldura narrativa da taverna, à noite e sob a influência do vinho. $\mathrm{O}$ traço natural que advém das correlações narrativas alinha os relatos ao fantástico estranho, o que é ampliado pela presença do extraordinário e das inúmeras correlações temporais que as narrativas articulam no alinhamento temporal. 
A utilização dos turnos narrativos e da metalinguagem que recupera personagens e acontecimentos descritos nos relatos individuais os ligando em nível profundo em uma coesão natural no conjunto de relatos. Este alinhamento e lança o insólito e o extraordinário das narrativas em direção às coincidências e encadeamentos naturais que unificam, por meio do encadeamento temporal, o grotesco à ambiência da moldura narrativa vista como possível, embora extraordinária, fato preponderante na classificação do fantástico estranho como elemento central dos relatos de Noite na taverna.

No âmbito deste artigo, focalizamos como o autor mobiliza o elemento sobrenatural para, por meio da gradativa racionalização desse traço, nos diferentes relatos em moldura de Noite na taverna, apontar para a transcendência ao real no momento de construção do ficcional em sua obra. Esta transcendência é aspecto importante do riso no conjunto de texto, mas direciona os relatos em um nível plausível, traço importante no fantástico presente na obra.

Dessa forma, entendemos que Noite na taverna, ao ser compreendida como um exercício metalinguístico, em relação à forma de manipulação do elemento natural no fantástico, sobretudo pela presença da moldura, é um importante exemplo da delimitação do confronto dialético entre natural e sobrenatural que se apresenta como central no fantástico; não só na obra em discussão, mas como centro da binomia azevediana, o que revela um traço consciente do autor em relação aos gêneros literários que mobiliza.

É evidente que o elemento grotesco conseguido pela ambiência insólita e pelo humor que cerca os relatos dos convivas à noite na taverna à noite e influenciado pelo vinho. Em nosso entendimento o que contribui para a presença do fantástico na obra é menos a embriaguês dos personagens; antes a presença do extraordinário das coincidências narrativas encadeadas na trama.

Dessa maneira, os relatos vão aos poucos caracterizando uma realidade complexa, na qual prevalece uma visão objetiva e, de certa forma, distanciada do universo sobrenatural apresenta como imanente aos relatos em uma leitura inicial. As ações aparentemente sobrenaturais descritas pelos personagens ao longo dos contos assumem, em nossa leitura, tons naturais e, com isso, situam o caráter fantástico de Noite na taverna no estranho.

À guisa de conclusão, lembramos que a advertência de "Solfrieri" quanto ao tom de ficção que envolve os relatos, em diálogo com a epígrafe retirada de Hamlet, modaliza o texto para o âmbito do verossímil/plausível, ou seja, do fantástico estranho, para retomarmos a caracterização do fantástico feita por Todorov (2003). Esta postura narrativa é, para nós, o primeiro argumento em favor da compreensão da obra nos limites do fantástico estranho. 


\section{Referências}

ADONIAS, Filho. Apresentação à Noite na taverna. In: AZEVEDO, Álvares de. Noite na taverna. 15. ed. Rio de Janeiro: Ediouro, 1996.

ALVES, Cilaine. O belo e o disforme: Álvares de Azevedo e a ironia romântica. São Paulo: Edusp/Fapesp, 1998.

AZEVEDO, Álvares de. Noite na taverna. 15. ed. Rio de Janeiro: Ediouro, 1996.

AZEVEDO, Álvares de. A lira dos vinte anos. 26. ed. Rio de Janeiro: Ediouro, 1998.

CAMILO, Vagner. Risos entre pares: poesia e humor românticos. São Paulo: Edusp, 1997.

CORTAZAR, Júlio. El sentimiento de lo fantástico. Conferência proferida na Venezuela, por Júlio Cortazar, em la U.C.A.B., em 1982. Disponível em: https://campus.almagro.ort.edu.ar/lengua/articulo/1332085/el-fantastico-segun-julio-cortazar . Acesso em: 06 dez. 2020.

HUGO, Victor. Prefácio de Cromwell. In.: GOMES, Álvaro Cardoso; VECHI, Carlos Alberto. A estética romântica: textos doutrinários comentados. Tradução Maria Antônia Simoes Nunes e Decílio Golombini. São Paulo: Atlas, 1992.

LE GOFF, Jacques. História e memória. Tradução Bernardo Leitão et al. Campinas, SP: Editora da UNICAMP, 1990.

LONGINO, Dionísio. Do sublime. Tradução de Marta Isabel de Oliveira Várzeas. Coimbrã: Imprensa da Universidade de Coimbrã. Disponível em: https://digitalisdsp.uc.pt/bitstream/10316.2/38162/1/Do\%20Sublime.pdf . Acesso em 01 dez. 2020.

SHAKESPEARE, William. Hamlet. 3. ed. Tradução de Péricles Eugênio as Silva Ramos. São Paulo: Abril Cultural, 1976.

TODOROV, Tzvetan. Introdução à literatura fantástica. 2. ed. São Paulo: Perspectiva, 2003. 